\title{
Comedy Matters: On the Impact of Comedy
}

\author{
Centre for Comedy Studies Research (CCSR) \\ Special Issue of Humor: International Journal of Humor Research \\ Guest Edited by Dr Sharon Lockyer \\ Director, Centre for Comedy Studies Research (CCSR)
}

The academic study of comedy has grown in volume, significance and reputation in recent years. The emergence of new international comedy conferences, book series, journals and programmes for comedy studies scholars have contributed to the growing interest in comedy studies. Although comedy studies scholars are still sometimes asked to 'tell a good joke' or questioned about why they study topics that, for some, are merely trivial and frivolous (and by implication should not be the topic of academic study), these requests are certainly becoming less frequent and less antagonistic. There is growing recognition both within academic circles and nonacademic communities that comedy is an important part of our contemporary lives that warrants academic attention and scrutiny. Another important influencing factor in the increasing recognition of comedy studies is the Centre for Comedy Studies Research (CCSR).

The CCSR is a large, high-profile and active international research centre devoted to the academic study of comedy. The CCSR was launched at Brunel University London, UK in October 2013 and has rapidly built a reputation as an international centre of research excellence in socially relevant comedy studies research. As an interdisciplinary centre it considers the production, content, reception and wider socio-political implications of comedy in its variety of formats and from a range of perspectives. A significant proportion of CCSR research specifically focuses on production and intention, which is an important distinction between comedy and humour (Mills, 2005). Comedy suggests 'material whose primary purpose is one of funniness, usually created by specific people with that aim, and understood as so by audiences', whereas a humorous situation is 'something that can have just happened, without a deliberate intention' (Mills, 2005: 17). This distinction results in different research agendas, research questions and data sources for comedy studies scholars and humour studies researchers. Despite this, their respective research findings and insights have mutual benefit for both fields - taken together comedy studies and humour studies research results in increased, in-depth and nuanced understanding and appreciation of the role, and impact, of production and intention.

The CCSR brings together leading academics, writers and practitioners from a diverse range of fields including sociology, communications, film and television, theatre, English, creative writing, business and management, psychology and social work. CCSR research areas encompass a number of overlapping themes including: broadcast and live comedy; comedy and identity; comedy, taboo and offence; comedy, power and ideology; comic novels; creativity and comedy; comedy and the everyday. CCSR research is strongly underpinned by the belief that comedy is socially, culturally, artistically, politically and economically significant at local, national 
and international levels.

This special issue of HUMOR, entitled Comedy Matters: On the Impact of Comedy, brings together a selection of CCSR researchers who are currently conducting innovative and important research within comedy studies. The special issue draws on, and showcases, the research presented at a number of the CCSR events held in its first year. These are: the

Launch Event, the Comedy Matters Research Seminar Series 2013-2014, the Comedy Matters: On the Impact of Comedy Symposium held at the International Society for Humor Studies (ISHS) Conference in Utrecht (2014) and the Sacha Baron Cohen Symposium.

The special issue includes an interesting mix of topics to illustrate the complex and broad-ranging ways in which comedy can be used in, and applied to, contemporary society. The eight articles included in this special issue are united in their shared interest in exploring the impact of comedy. The articles examine the dynamic performative, social, cultural and psychological impact of a range of comedy formats and examples, from jokes told in everyday life and/or face-to-face interaction (McCreaddie; Pickering, Gironzetti, Huang and Attardo), to clowning (Peacock), through to live stand-up comedy (Quirk), mediated comedy (Mills; Milner Davis; Hirzalla and van Zoonen; Weaver and Bradley) and other cultural products (Milner Davis), for both lay and professional comedy producers and comedy audiences. The impact of comedy in a range of contexts, from healthcare interactions through to conflict areas and warzones, is considered.

The special issue brings together, for the first time, emerging and established comedy studies scholars. Furthermore, the articles are multidisciplinary drawing across media and communications (Hirzalla and van Zoonen; Weaver and Bradley), nursing and health studies (McCreaddie), drama and theatre (Peacock; Quirk), linguistics (Pickering, Gironzetti, Huang and Attardo), cultural studies (Milner Davis) and film and television studies (Mills). In addition to illustrating how comedy studies holds a prominent position on the academic landscape, the special issue aims to ignite future research into one of the most dynamic, complex and contradictory features of our lives. I hope you enjoy reading it as much as I have enjoyed working on this special issue.

\section{References}

Mills, Brett. 2005. Television Sitcom. London: British Film Institute.

\section{Acknowledgments}

First and foremost I would like to thank Professor Giselinde Kuipers, HUMOR Editorin-Chief, for her passionate belief in the special issue and the CCSR. It is due to your commitment and vision that our informal chat at the International Society for Humor Studies (ISHS) conference in Utrecht in 2014 about the potential of a CCSR special issue of HUMOR has come to fruition. Many thanks to everyone at the HUMOR journal and De Gruyter Mouton publishers for their indispensable work. I would also like to send my grateful thanks to all of the contributors to the special issue. From the outset, all of the contributors have demonstrated their support for 
both the CCSR and the special issue. The CCSR and this special issue would not exist without the continued backing of colleagues at Brunel University London many thanks to everyone from across the institution for your belief in the CCSR. Grateful thanks also to everyone external to Brunel University London for attending events, sharing your ideas and endorsing comedy studies.

Sharon Lockyer is the Founding Director of the Centre for Comedy Studies Research (CCSR) and a Senior Lecturer in Sociology and Communications in the Department of Social Sciences, Media and Communications at Brunel University London, UK. Her research interests include critical comedy studies, identity politics and comic media representations and the sociology of popular culture Contact email: Sharon.Lockyer@brunel.ac.uk 